\title{
Group-based Formative Assessment: A Successful Way to Make Summative Assessment Effective
}

\author{
Haishen $\mathrm{Yu}$ \\ Hebei Normal University for Nationalities, Chengde, Hebei, China \\ Hongmei Li \\ Chengde No. 12 Middle School, Chengde, Hebei, China
}

\begin{abstract}
In this study, I mainly examine the effectiveness of group-based self-assessment of exam review with regard to improvement in comprehension. Furthermore, I also examined students' perception of this method. Some students worked collaboratively to review an exam through group-based formative assessment activity, while the other students reviewed the exam without the group-based formative assessment activity. All of them retook the exam with the same content with scrambled response options. The result shows that students exposed to the group-based formative assessment method demonstrated an improvement of over $10 \%$ in their test scores, whereas scores for students in the control group (class two) improved by only $2.4 \%$. In other words, students subjected to the group-based formative assessment method performed significantly better than the control class. The results of the student survey also favored the group-based formative assessment activity.
\end{abstract}

Index Terms - group-based formative assessment, examreview, effectiveness

\section{INTRODUCTION}

Recently, more and more educatiors began to recognize the important role of assessment in the process of learning. However, not all the people have understood the meaning and the purpose of assessment. Cizek (1997) defined the assessment as "the planned process of gathering and synthesizing information relevant to the purposes of (a) discovering and documenting students' strengths and weaknesses, (b) planning and enhancing instruction, or (c) evaluating progress and making decisions about students"(p. 5). From this definition, we can have an understanding of the purpose of assessment.

However, according to Torrance and Pryor (1998), many teachers they interviewed "seemed to regard 'assessment' as a distinct activity from 'teaching' ... rather than to benefit themselves and/or their pupils" and "assessment was perceived as a formal activity oriented to producing valid and reliable summative measures of performance"(p. 43). Surely assessment can be regarded as the summative measurement or evaluative method of the student's learning and achievement. But, assessment can play more important role in the learning. That is the formative use of assessment.

Many people still do not fully understand the formative assessment, so there is a need to show an explanation of formative assessment. In this essay, I will make a discussion on formative assessment. In the first part, I will make a literature review of formative assessment. Next, the combination of formative assessment and summative assessment will be discussed. Finally, I will make a study to examine the effectiveness of group-based formative assessment with regard to students' improvements in comprehension.

\section{The Literature REVIEW OF Formative ASSESSMENT}

\section{A. The Concept of Formative Assessment}

Formative assessment is generally defined as the process "taking place during a course with the express purpose of improving pupil learning" (Torrance and Pryor, 1998, p. 8). According to Bell and Cowie (1999), formative assessment is "the process used by teachers and students to recognise and respond to student learning in order to enhance that learning, during the learning" (p. 198). Carol (2002) regard formative assessment as a diagnostic use of assessment to provide feedback to teachers and students over the course of instruction. Black (2003) reclaims the extend definition of formative assessment, "assessment for learning is any assessment for which the first priority in its design and practice is to serve the purpose of promoting pupils' learning" (p. 3).

B. The Key Components of Formative Assessment

According to McCallum (2000), key components of formative assessment can be described as: regular planned 'assessment incidents'; regular pupil self-assessment; feedback for learning; adjusting teaching to take account of the results of assessment. 
1. Regular planned 'assessment incidents'

McCallum (2000) has shown the evidence that regular and planned assessment incidents are part of formative assessment. If teachers were made more conscious of the pupil organization and lesson structure, they could make even short interactions more formatively useful. Assessment incidents are focused on small group tasks seems reasonable; Open-style activities offering the opportunity for collaboration are more useful; McCallum (2000) argues that an overt listener-observer/note-taker role is essential to learn about how and what pupils know, understand and can do. But the teacher also needs to use questions to provoke thinking. 'Observe, wait, listen, question' is a useful sequence to follow; Assessment incidents need to be systematically planned and carried out several times a week.

2. Regular pupil self-assessment

Black and wiliam (1998) states that the link of formative assessment to self-assessment is not an accident-it is indeed inevitable. McCallum (2000) claims that regular pupil self-assessment is an important part of formative assessment. Black and wiliam (1998) emphasize the importance of training the students' self-assessment ability. "For formative assessment to be productive, pupils should be trained in self-assessment so that they can understand the main purposes of their learning and thereby grasp what they need to do to achieve" (Black and Wiliam, 1998, p. 141). They also claim "self-assessment by pupils... is in fact an essential component of formative assessment" (Black and Wiliam, 1998, p. 141). Self-assessment should involve both reflection on one's learning strategies and analysis of one's work.

3. Feedback for learning

Sadler (1989) assert that the feedback about the students' efforts in learning has three elements- the desired goal, the evidence about their present position, and some understanding of a way to close the gap between the two. The teacher should focus feedback on tasks and the learning strategies used by students; the teacher should use descriptive feedback that gives details of why answers are correct or wrong; the teacher should also consider of the public/private and oral/written dimensions of feedback and how feedback could be tailored to individuals. Bell and Cowie (1999) stress that feedback is an essential component of formative assessment interaction (Clarke, 1995; Sadler, 1989 cited by Bell and Cowie, 1999)

4. Adjusting teaching to take account of the results of assessment

The purpose of formative assessment is to promote the students' learning through the feedback from both the teacher and the students. In order to achieve this purpose, the teacher must adjust the teaching from time to time to close the gap between the students' desired goal and their present position. According to the feedback teachers should adjust their teaching way from delivery of learning to guiding and coaching students own learning activity.

\section{The categories of formative assessment}

According to Bell and Cowie (1999), two forms of formative assessment has been using by the teachers and students in the classroom. That is planned formative assessment and interactive formative assessment. "The process of planned formative assessment was characterized by the teachers eliciting, interpreting and acting on assessment information" (Bell and Cowie, 1999, p. 203). The assessment was planned by the teacher before the class. In order to realize the purpose for promoting the students' learning, the teacher should elicit the question at the beginning of the class, and then collect the information about students learning according to their feedback, so the teacher can determine his action on the content of the class. The process of this assessment can circle around during the whole class. Interactive formative assessment always takes place during student-teacher interactions. The details of interactive formative assessment are not planned and cannot be anticipated. According to Bell and Cowie (1999), the process of interactive formative assessment involves the teachers noticing, recognizing and responding to student thinking during the interactions. In order to realize the purpose for promoting the students' learning, the teacher should notice the students' problem during their interaction, and then recognize that some teaching is required, so the teacher will resolve the problem as a response.

Bell and Cowie (1999) state that the main distinction between planned and interactive formative assessment are the degree and type of planning done by the teachers and the purpose of the formative assessment. The teachers can make a detailed plan for the planned formative assessment in advance of a lesson. They can make a plan of the specific activities in the class, such as what kind of information to get; how to get the information. This kind of formative assessment is more formal. The planning of interactive formative assessment is not so concrete. The teachers can just prepare to notice and recognize the students' ideas and plan to respond to them. It can not be anticipated because it usually happens during the halfway of the lesson. Sometimes the teachers have to change the purpose and plan of that class. So it is more intuition.The purpose of planned formative assessment is to gain the information about the progress of the learning from all the students in order to promote the learning. This is the initial purpose of the lesson. The purpose of interactive formative assessment is to reconcile the learning of individual students. The purpose of interactive formative assessment evolves or emerges from what was happening in the lesson.

\section{The Combination of Summative Assessment AND Formative AssENMENT}

Assessment techniques have long been used to monitor student learning by educators. These techniques are often used in the form of summative assessment, which consists of examinations of student learning. Summative assessment "generally takes place after a period of instruction and requires making a judgment about the learning that has occurred" 
(Carol, 2002, p. 9). The goal of summative assessment is to "measure and communicate pupil performance for the purpose of certification and accountability" (Torrance and Pryor, 1998, p. 8). Summative assessment is used to summarizs students' achievement, usually in the form of grades. (Bloom, Hastings, \& Madaus, 1971). The original purpose of summative assessment was to differentiate among students with regard to level of achievement (Wininger, 2005).

However, assessment can serve many purposes in educational settings. Formative assessment provides feedback about learning progress in order to improve learning and instruction to both student and teacher. Wininger and Norman (2005) defined Formative assessment as the measurement of student progress before or during instruction for the purpose of modifying instruction and improving student performance. Reviews of studies on formative assessment reveal that classroom use of formative assessment results in substantial learning gains (Black \& Wiliam, 1998; Fuchs \& Fuchs, 1986). Formative assessment is both a measure of student achievement and a means for instructors to assess their instructional practices and for students to monitor their own learning strategies, with the goal of increasing student performance (Wininger \& Norman, 2005).

There are mainly two distinctions between summative assessment and formative assessment. First, the main distinction between the two types of assessment is the purpose of the assessment. Summative assessment is for certification and accountability and the purpose of formative assessment is to improve the students' learning. Second, the two types of assessment are carried out in different time. "Summative assessment is generally considered to be undertaken at the end of a course or programme of study" (Torrance and Pryor, 1998, p. 8). Formative assessment generally happens during the process of the course or learning.

Wininger (2005) proposed a combination of assessment techniques through formative summative assessment . According to Wininger, formative summative assessment entails reviewing exams with students so that they get feedback about their comprehension of concepts. Wininger evaluated the synthesis of summative assessment and formative assessment in an empirical way with very promising results. Wininger (2005) found that his method of reviewing exams with his undergraduate psychology students, which prompted analysis and critical thinking, was regarded favorably by the students and resulted in greater retention of concepts.

\section{Providing Effective FeEdBack by Group-BASEd SELF-ASSESSMENT}

The over use of summative assessment without student feedback have been criticized by researchers during the past few years. It means that the practice of giving exams for the purpose of assessment without providing feedback on the examination material is denounced. Wiliam \&Black (1996) states that a notable feature of formative assessment is feedback - both to the instructor and to the student - about the learning process. We think of feedback as essential for learning. D. Royce Sadler(1989) tried to show why students so often failed to improve, even when teachers provided accurate feedback. Sadler (1989) argued that it was insufficient simply to point out right and wrong answers to students. Feedback is very effective for students to close the gap between their current and expected performance. Biggs (1998) suggest that formative assessmentis a very effective practice to enhance student learning. Black \& Wiliam (1998) and Fuchs \& Fuchs (1986) have proved that formative assessment can be more effective to improve student performance.

Sadler (1989) wanted to develop evaluative expertise in students so they could become proficient at monitoring their own learning. Student self-assessment is not about saving teachers from the work of grading papers. It can be a deeply principled practice that serves both metacognitive and motivational purposes when used in a way that develops student thinking. Self-assessment makes students more conscious about their own learning and inhance the relationship between teacher and student. Klenowski (1995) reports that students are more clearabout the assessment criteria and became more reflective in their judgments. Students are more interested in teacher comments and feedback than in grades.

According to Harton, Richardson, Barreras, Rockloff, \& Latane (2002) and Woody, Woody, \& Bromley (2008), collaboration is very effective to increase students' performance. Harton, H. C., Richardson, D. S., Barreras, R. E., Rockloff, M. J., \& Latane, B. (2002) made a study about an interactive learning technique in several undergraduate psychology classes and found that students' performance greatly improved in content- focused discussions with other students. Crooks (1988) claims that students' collaboration ability may also increase motivation, develop self-evaluation skills and improve interpersonal relationships.

In the first stage of this study, I mainly examine the effectiveness of group-based self-assessment of exam review with regard to improvements in comprehension. Futhermore, I also examined students' perception of this group-based formative assessment method.

\section{METHOD}

\section{A. Participants}

Participants were 83 students who are studying in a middle school in a small city in North of China. They are from two classes (class one with 41 students and class two with 42 students) of Grade Eight. The course of English for Class one met on 8:10 a.m. from Monday to Friday, and Class two's English class met on 9:05 a.m from Monday to Friday. The period of each class is 45 minutes. The same English teacher taught both classes. The students (43 girls, 40 boys) had an average age of 14. All students attended the first exam and the review day, and all completed the postreview exam 
(administered one week after the exam review day). The postreview examination in each class included questions based solely on the materials covered in that former exam.

\section{B. Procedure}

Students (in both calss one and two) took the first English exam (during each semester, students usually take four exams as summative assessment to evaluate teachers's teaching and students's learning by the school) consisting of multiple-choice, vocabulary and grammar, cloze, reading comprehension and writing. The exam content spanned two units. This exam was the students' first in the class. When giving each exam, the English teacher told the students that the exam will be reviewed om the next class. The teacher used group-based formative assessment method in the 8:10 class (class one). The teacher divided the students into groups of 4 or 5 persons. Each group was ensured to include at least 1 person at each grade level for the exam. There was at least 1 person 1 with a Pass, 1 with a Good, 1 with an Excellence in each group. The teacher askeded students to work cooperatively and to consider the ideas of each group member before reaching a final answer. In each review class, students have 30 minutes to complete the activity and then were given the correct answers for all questions. For the 9:05 class (class two), the teacher gave each student a copy of his or her own exam and at the same time, the correct answer was given to the students. The teacher instructed students to use their notes and books to answer all of the questions from the exam. The teacher instructed students to ask questions for clarification or understanding. They also received the same amount of time (30 minutes) to go over the exams.

Students took the same exam again one week after the reviewing of the exam. All the students of the two classes did not know that they would retake the exam before the class in which they took it. However, the 8:10 a.m. class received the group-based formative assessment method argue that the 9:05 a.m. class may have known about the retake from the 8:10 a.m. class, so that students in the 9:05 a.m. class have time to study for the retake briefly. In addition, to be fair to the 9:05 a.m. class, they did receive the group-based formative assessment method after the retake.

\section{Measures}

The effectiveness of the group-based formative assessment method was measured through two ways: postreview tests and anonymous surveys of student opinions.

1. Postreview test

To measure learning and undersdanding of key knowledge related specifically to the exam review sessions, the teacher asked the students to retake the exam one week after the review day. The options of the response on the retake exam were scrambled, but the exams were exactly the same in content.

2. Student surveys

In order to assess whether the group-based formative assessment exam review activity useful and enjoyable for the students, students at 8:10 ( class one ) completed surveys anonymously after the retake of the exam. Six scaled questions and one open-ended question for general comments were included in the surveys. (see Table 1)

TABLE 1.

MEANS AND STANDARD DEVIATIONS FOR STUDENT EVALUATION OF GROUP-BASED FORMATIVE ASSESSMENT ACTIVITY

\begin{tabular}{|l|l|}
\hline Questions & M \\
\hline 1. Review the exam in groups helps me to understand. & 4.51 \\
\hline 2. I like discussing and learning with classmates. & .55 \\
\hline 3. I think there is a chance to ask questions during the review. & 4.12 \\
\hline 4. Review the exam in groups is a worthwhile use of class time. & .97 \\
\hline 5.I want to study in groups for the next exam & 4.27 \\
\hline 6. I would like this group-based formative assessment activity in other classes. & 4.32 \\
\hline
\end{tabular}

Note. The scale ranged from 1 (strongly disagree) and 5 (strongly agree).

\section{RESULTS}

\section{A. Quantitative Analysis of Student Learning}

The average scores for each class on the initial administration of the exam were 78.2 for class one and 79.1 for class two. Average scores on the retake were 88.3 for class one and 81.5 for class two. There were no significant differences between the two classes on the initial exam administration. However, students (in class one) who received the group-based formative assessment method scored significantly higher on the retake. They made an improvement of over $10 \%$ in their exam scores, whereas scores for students in class 2 improved by only $2.4 \%$. In other words, students subjected to the group-based formative assessment method performed significantly better than the control class (class two).

\section{B. Student Surveys}

The results of the student survey also favored the group-based formative assessment activity. As shown in Table 1, students rated the group-based reviews favorably and similarly in terms of their overall usefulness. Students also indicated a high and similar level of interest in having more exam reviews after the review activity. Students' responses in the survey indicated that they believe that the group-based formative assessment method made them become more clarified and understanding about the exam items. Students also found that they have made a good use of class time with this 
method and that they expect this type of feedback being used in other classes.

\section{DISCUSSION}

This study shows that formative feedback can also come from other students. In this study, students worked collaboratively to review an exam through group-based formative assessment activity. With regard to undersanding of key knowledge, The students who participated in the group-based formative assessment activity performed distinctively better (on average) on the retake of the same material exam one week later than they did on the initial test. In contrast, students without participating in group-based formative assessment activity did not show a significant increase in the undersanding of key knowledge on subsequent individual retests. Furthermore, a significantly greater part of students retained or increased their knowledge after the group-based formative assessment activity. These findings are especially promising on consideration that the students who were mot motivated for learning theknowledge in the review of the exam.

On students' enjoyment of the group-based formative assessment activity, students rated the activity very positively in helping them form closer relationships with their classmates. Moreover, students also have a stronger desire to work in the form of study groups in other subjects because of the group-based formative assessment activity. Therefore, the group-based formative assessment activity was proved to have a positive effect on students' interactions and students' motivation to participate in collaborative learning activities.

The design of this study still have some limitations. It is difficult to know whether students who made improvement on the retake of the exam had gained a deeper understanding of the material or had only memorized the answers. Because the original exam and the retake of the exam (given one week later) were composed of the same questions with only scrambled orders of the answers. Therefore, a test of the same material using different questions might be a more useful measure of learning.

The group-based formative assessment method has the potential to serve additional purposes beyond enhancing student learning. The teacher can receive feedback about the gaps in teaching methods or student learning. Shepard (2005) states that our aim should be to establish classroom practices that encourage peer assessment, regard errors as opportunities for learning, and promote shared thinking.

\section{REFERENCES}

[1] Biggs, J. (1998). Assessment and classroom learning: A role for summative assessment? Assessment in Education: Principles, Policy \& Practice, 5, 103-110.

[2] Bell, B. (2000). Formative assessment and science education: a model and theorizing. In Millar,R.; Leach, J. \& Jonathan, O. (Eds.), Improving science education: the contribution of research.(pp48-61), Bukingham: Open University Press.

[3] Bell, B \& Cowie, B. (1999). Researching formative assessment. In Loughran, J. (Ed.), Researching teaching: methodologies and practices for understanding pedagogy. (pp198-214)London: Falmer Press.

[4] Black, P.; Harrison, C.; Lee, C.; Marshall, B. \& Wiliam, D. (2003). The Nature and Value of Formative Assessment for Learning. London: School of Education, King's College.

[5] Black, P., \& Wiliam, D. (1998). Inside the black box: Raising standards through classroom assessment. Phi Delta Kappan, 80, 139-148.

[6] Bloom, B. S., Hastings, J. T., \&Madaus, G. F. (Eds.). (1971). Handbook on the formative and summative evaluation of student learning. New York: McGraw-Hill.

[7] Boston, Carol (2002). The concept of formative assessment. Practical Assessment, Research \& Evaluation, 8:9.

[8] Cizek G. J. (1997). Learning, achievement, and assessment: constructs at a crossroads. In Phye,G.D. (ed.), Handbook of classroom assessment: learning, achievement, and adjustment. California: Academic Press, Inc.

[9] Crooks, T. J. (1988). The impact of classroom evaluation practices on students. Review of Educational Research, 58, 438-481.

[10] Drouin, Michelle A. (2010), Group-Based Formative Summative Assessment Relates to Improved Student Performance and Satisfaction. Teaching of Psychology, 37:114-118

[11] Crumrine, Tom \& Demers, Chris. (2007), Formative Assessment: Redirecting the Plan. The Science Teacher,74, 6:64-68

[12] Fuchs, L. S., \& Fuchs, D. (1986). Effects of systematic formative evaluation: A meta-analysis. Exceptional Children, 53, 199-208.

[13] Harton, H. C., Richardson, D. S., Barreras, R. E., Rockloff, M. J., \& Latane, B. (2002). Focused interactive learning: A tool for active class discussion. Teaching of Psychology, 29, 10-15.

[14] Klenowski, V. (1995), Student selfevaluation process in student-centered teaching and learning contexts of Australia and England. Assessment in Education, 2, 145-163.

[15] Linn, R. L., \& Gronlund, N. E. (2000). Measurement and assessment in teaching (8th ed.). Upper Saddle River, NJ: Prentice Hall.

[16] McMillan, J. H. (2001). Classroom assessment: Principles and practice for effective instruction (2nd ed.). Boston: Allyn \& Bacon.

[17] Sadler, D, R. (1989). Formative assessment and the design on instructional systems. Instructional Science, 18(2), 119-144

[18] Shepard, L. A. (2000). The role of assessment in a learning culture. Educational Researcher, 29(7), 4-14.

[19] Shepard, L. A. (2005). Linking formative assessment to scaffolding. Educational Leadership, 9,66-70

[20] Stiggins, Rick. (2005). From Formative Assessment to Assessment for Learning: A Path to Success in Standards- Based Schools. The Phi Delta Kappan, ,87, 4: 324-328 
[21] Torrance, H. and Pryor, J. (1998). Investigating Formative Assessment. Teaching, Learning and Assessment in the classroom. Buckingham, Open University Press.

[22] Vygotsky, L. S. (1978). Mind in society. Cambridge, MA: MIT Press.

[23] Wexley, K. N., \& Thornton, C. L. (1972). Effect of verbal feedback of test results upon learning. The Journal of Educational Research, 66, 119-121.

[24] Wiliam, D., \& Black, P. (1996). Meanings and consequences: A basis for distinguishing formative and summa tive functions of assessment? British Educational Research Journal, 22, 537-549.

[25] Wininger, S. R. (2005). Using your tests to teach: Formative summative assessment. Teaching of Psychology, 32:164-166.

[26] Wininger, S. R., \&Norman, A. D. (2005). Teacher-candidates' exposure to formative assessment in educational psychology textbooks: A content analysis. Educational Assessment, 10, 19-37.

Haishen $Y \mathbf{u}$ is a lecturer of English at Hebei Normal University for Nationalities, in Chengde, Hebei, China. He received his Master of Education from Waikato University in New Zealand in 2004. He has worked with ESL students for 15 years. His research interests include second language acquisition, Applied Linguistic and critical pedagogy.

Hongmei Li is a teacher of English at Chengde NO. 12 Middle School in Chengde, Hebei, China.She received her Bachelor's degree of English from Hebei Teachers' University in 2000. She has been teaching English for over 10 years. Her research interests include second language acquisition and Cooperative Learning. 